\title{
In-situ material flow pattern around probe during friction stir welding of austenitic stainless steel
}

\author{
F.C. Liu*, and T.W. Nelson* \\ Department of mechanical engineering, Brigham Young University, Provo, UT 84602, USA
}

\begin{abstract}
The probe route as well as the material flow around the keyhole during weld termination were tracked and used to determine the probe position just prior to weld termination. This approach enables analysis of in-situ microstructure distribution and the nature of material flow during friction stir welding (FSW). A FSW flow model was established. During steady state FSW, the material at the advancing side (AS) recrystallized rapidly when it was swept by the hot rotating probe. The recrystallized grains were driven to rotate around the probe along the tool rotation direction, forming the material flow zone (MFZ). As the base material approached the probe, it was compressed initially, forming a compression zone (CPZ) mainly consisted of coarse deformed grains. When the coarse deformed grain in CPZ collided with the hot material in the MFZ, it recrystallized and added into the MFZ, thickening the MFZ ahead of the probe. During FSW, the material intersecting the path of probe was displaced to rotate around the probe and then deposited behind the probe at roughly the same transverse position as its initial position.
\end{abstract}

Keywords: Friction stir welding; Friction stir processing; Stainless steel; Material Flow; Visualization; Electron backscatter diffraction (EBSD)

F.C. Liu, E-mail: fchliu@ alum.imr.ac.cn, Tel: +1 801-422-5189, Fax: +1 801-422-0516.

T.W. Nelson, E-mail: nelsontw@byu.edu, Tel: +1 801-422-6233, Fax: +1 801-422-0516. 


\section{Introduction}

Friction stir welding (FSW) is an innovative solid-state joining process in which a nonconsumable tool is used to 'stir' the joint materials to produce a high quality joint with a fine microstructure and superior mechanical properties [1- 5]. FSW is considered to be one of the most significant welding techniques to emerge in the past two and a half decades. Although FSW was initially developed for joining low melting point metals, such as Al, and Mg alloys [6-9], research in FSW of steels has grown with the development of effective welding tools.

A complete understanding of the material flow and microstructure evolution during FSW process is a key element in understanding the development of weld defects, and post-weld microstructure and properties. Although some researchers have investigated the material flow behavior during FSW, the existing theories are still inconclusive and often contradictory. This is because the material flow during FSW is complicated, varies with workpiece material and welding parameters, and cannot be observed directly.

Marker insert technique has been used to track the material flow during FSW. For example, Colligan [10] embedded steel shots with a diameter of $0.38 \mathrm{~mm}$ along the welding path of aluminum alloys and showed the shot distribution with the aid of X-ray tomography after suddenly stopping the forward motion of the welding tool. Morisada et al. $[11,12]$ showed the three-dimensional flow pattern of a $0.3 \mathrm{~mm}$ spherical tungsten tracer during FSW using two pairs of X-ray transmission real time imaging systems. Although all experiments clearly indicate that weld material is displaced around the welding tool, there are some concerns in that the tracers of vastly different density than the matrix may not properly represent the actual material flow.

As foreign material with similar density and thermomechanical properties as the base material but with other composition is selected as tracer, the tracer and base material will deform 
and flow in a similar manner. Reynolds [13] has used Al alloy 5454 sheet as a marker material for FSW of Al alloy 2195. After a comparison of the initial and final positions of the marker, they deduced that the FSW process can be roughly described as an in situ extrusion process wherein the tool shoulder, the weld back plate and the cold base metal outside the weld zone form an 'extrusion chamber' which moves relative to the workpiece. Schmidt et al. [14] insert copper strip as marker material for FSW of $\mathrm{Al}$ alloy 2024. The distribution of the copper around the probe and in the weld region was recorded by X-ray and computer tomography (CT) techniques. Based on experimental and simulation results, Schmidt et al. considered that the flow zone during FSW process consisted of rotation zone, transition zone and deflection zone from the probe surface to the base material. Each zone was closely related to its corresponding flow pattern.

The material flow can also be deduced from the micro-textures since the deformation history can be recorded by the crystallographic distribution of the deformed material. Sato et al. [15] and Field et al [16] have examined the micro-texture in FSW Al alloys using electron backscatter diffraction (EBSD) and found that the stir zone had a texture component with the $\{111\}$ plan and $<110>$ direction roughly parallel to the probe column surface and the pin rotation direction, respectively. The investigations on FSW of Mg alloys [17-19] showed that an intense (0002) basal plane texture surrounding the probe column surface was produced in the stir zone. For FSW of commercial pure Ti, The P-fiber texture with a pronounced $\{10 \overline{1} 0\}<11 \overline{2} 0>$ component which rotated from the retreating side (RS) to AS following the rotation of the shear direction across the stir zone were detected [20-22]. These observations indicated that the material flow during FSW mainly arose from the simple shear deformation around the probe. Because only the 
initial and final microstructure was examined, a full story about the material flow and microstructural evolution during FSW cannot be summarized from these fragments.

FSW keyholes have been made through 'freezing' the FSW process by the method of stopping the tool and immediately quenching the work piece ('stop action' technique) [18,23-25]. The microstructural investigation around the 'frozen' keyhole provided meaningful insights on the microstructure evolution and material flow. However, the rotating tool cannot be stopped instantly due to the inertia in the FSW system. The tool rotation as a result of inertia disturbing the material distribution around the probe. Additionally, probe shift caused by relaxation in the FSW system allowed the keyhole position to shift during weld termination, resulting in a keyhole microstructure that does not represent the in-situ material distribution during steady state FSW. In the experiment of Prangnell et al. [23], the tool rotation was stopped within 0.1 seconds after activating the emergency stop, a shift of probe occurred due to system relaxation is evident. This indicates that the material flow around the so called 'frozen' keyhole is not consistent with that around a probe during steady state FSW.

Because the FSW system relaxation and probe shift during weld termination cannot be totally avoid, a fundamental understanding about the system relaxation and what actually happed during the period from activation of weld termination to cessation of probe rotation is required. For this purpose, various techniques such as emergency weld termination, weld force monitoring, tracer technique and EBSD examinations were performed with great care in this study. The final objective is to present the in-situ material flow pattern during a steady state FSW.

\section{Experimental details}

Hot rolled commercial 304L austenitic stainless steels with a thickness of $12.7 \mathrm{~mm}$ were welded using the TTI-RM2 FSW machine. All welds were made Polycrystalline Cubic Boron 
Nitride (PCBN) Convex-Scrolled-Shoulder-Step-Spiral (CS4) tools with a shoulder 25 in diameter and a frustum probe $9 \mathrm{~mm}$ in root diameter, $5 \mathrm{~mm}$ in tip diameter and $3.8 \mathrm{~mm}$ in length. The tool rotation rate, welding speed and downward force is $250 \mathrm{rpm}, 100 \mathrm{~mm} / \mathrm{min}$ (i.e. the workpiece traveled at a speed of $100 \mathrm{~mm} / \mathrm{min}$ ), and about $8 \mathrm{kN}$, respectively. A liquid cooled tool holder equipped with telemetry system was used. An argon shielding system was applied to minimize the workpiece surface oxidation. The temperature and the welding force in three dimensions were monitored during FSW.

One weld was terminated in a traditional way, i.e. reducing the welding speed to zero while maintaining tool rotation in its original speed and then extracting the rotating weld tool. The keyhole obtained at the end of this weld is identified as keyhole I. An emergency stop was used for another weld, i.e., terminating the workpiece travel and tool rotation as fast as the machine is capable. The probe remained in the workpiece after weld termination to reduce the system relaxation. The keyhole obtained at the end of this weld is identified as keyhole II. In order to reveal the material deposition during FSW, commercial 1008 low carbon steel slices were inserted in to the 304L austenite stainless steel as marker material and subjected to FSW as theses steels have similar thermal mechanical properties. Negligible temperature fluctuation was observed when the welding tool entered the region containing 1008 steel slices.

The workpiece travel was stopped within 0.01 second after activating welding termination for all the welding, resulting a longitudinal movement of less than $15 \mu \mathrm{m}$. Such a negligible shift was not considered in this study. For keyhole II, the tool rotation stopped completely 0.6 second after activating weld termination. To prevent significant grain growth, coolant was poured around the keyholes immediately after finishing FSW for all the welding. The keyholes were cooled to less than $200^{\circ} \mathrm{C}$ within 10 second. 
The samples for optical examinations were mechanical polished and then were electrolytic etched in a solution composing of $10 \mathrm{~g}$ oxalic acid and $100 \mathrm{ml}$ distilled water. The EBSD samples were vibratory polished using $0.05 \mu \mathrm{m}$ colloidal silica after a standard mechanical polishing. High resolution EBSD data were obtained at $20 \mathrm{kV}$ at steps of $0.2 \mu \mathrm{m}$ using FEI Helios Nanolab 600 with a TSL channel EBSD system. FEI Helios Nanolab 600 permitted more than one million EBSD data each hour and so that large-sized high-resolution EBSD maps were obtained in this study.

\section{Results and analysis}

\subsection{Probe travel route during weld termination}

The most accurate way to determine the system relaxation during weld termination is to evaluate the change of interaction forces between the workpiece material and the welding tool. Fig. 1 shows the forces on the probe during the process of welding and weld termination. For Keyhole I (Figs. 1a and b), the downward force decreased to zero immediately after weld termination. The transverse and longitudinal forces turn negative first and then went back to zero 2 second after activation of weld termination. After activation of weld termination for Keyhole II, all probe forces decreased sharply in the initial 0.6 second, followed by a gradual decrease. The force change demonstrated that a tradition weld termination at keyhole I allowed the FSW system to relax completely. System relaxation also occurred in keyhole II during the emergency weld termination but the relaxation forces was significantly less.

The force in transverse and longitudinal directions was caused by the spindle deflection of the weld system. The relationship between beam deflection and the bending forces can be described by Eq. 1 [26]:

$\delta=F L^{3} / C_{1} E I$ 
where $\delta$ is deflection, $F$ is bending force, $L$ is beam length, $C_{l}$ is a dimensionless constant associated with force distribution, $E$ is Young's modulus, $I$ is a section shape parameter. Eq. 1 shows that the beam deflection has a linear relationship with the bending force for a given beam. Therefore, the probe position (i.e. the deflection of FSW spindle apex) during weld termination can be estimated by the reaction forces according to their linear relationship. The results were qualitatively show in Fig. 2.
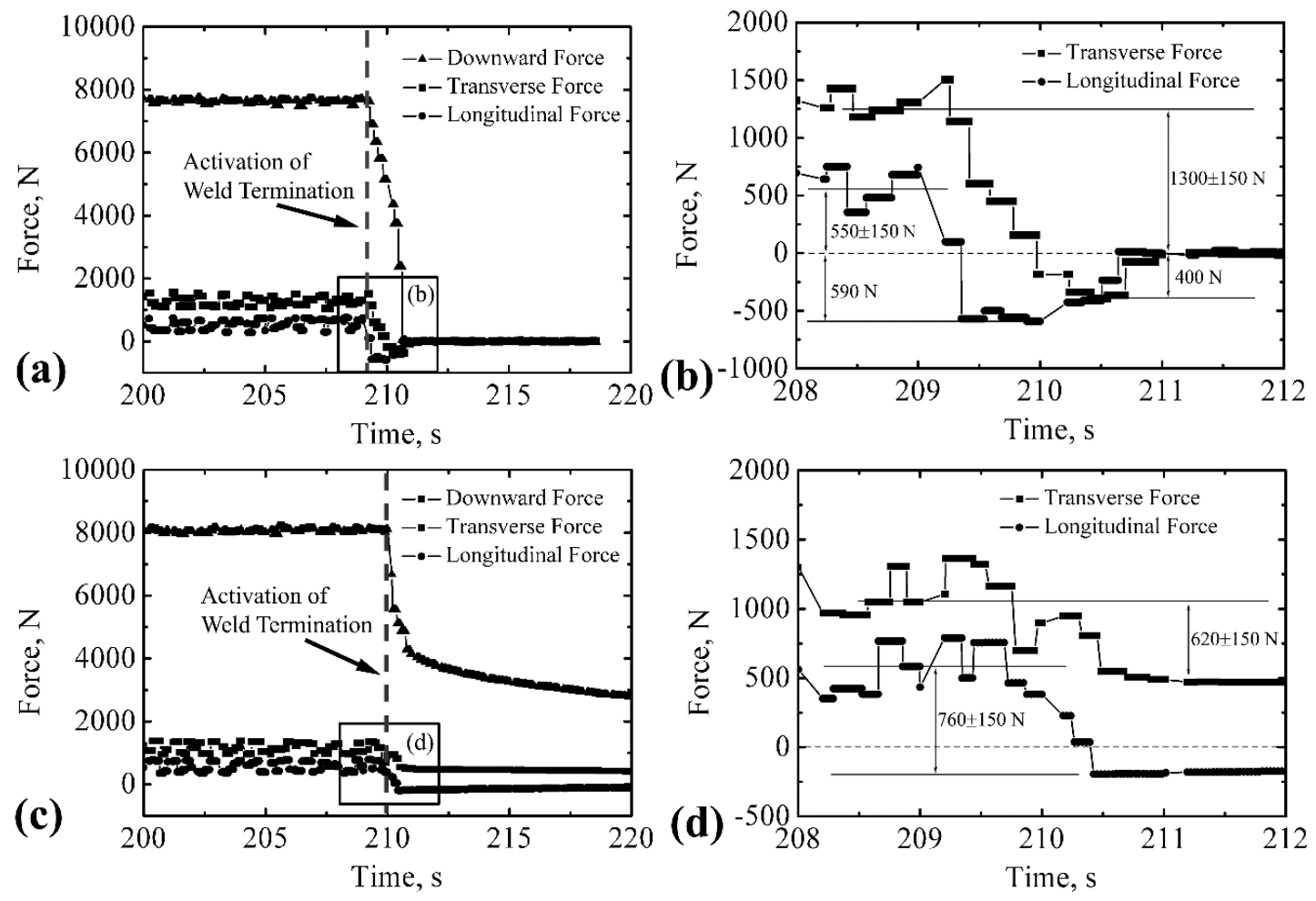

Fig. 1. Reaction forces between workpiece material and welding tool close to ((a) and (b)) keyhole I and ((c) and (d)) keyhole II. (Data were acquired at a frequency of 9 Hert, therefore, some flats appeared). 


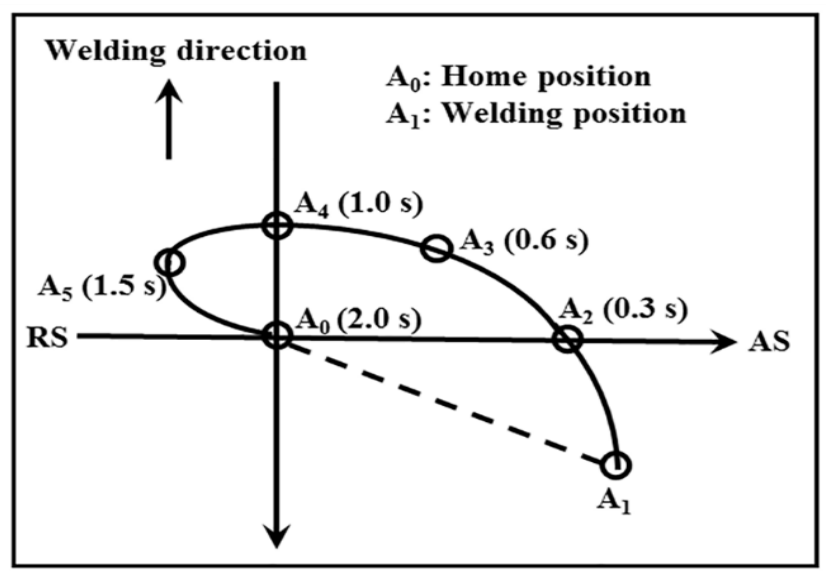

Fig. 2. Pin travel route during weld termination.

Fig. 2 shows that the probe was pushed away from its "home" position $\left(\mathrm{A}_{0}\right)$ to its weld position $\left(\mathrm{A}_{1}\right)$ during steady state FSW due to the reaction force during welding. After the activation of weld termination, the workpiece travel in the weld direction terminated immediately but the probe continued to rotate. In this case, the probe position in keyhole I moved back to its "home" position along the route of $\mathrm{A}_{1}-\mathrm{A}_{2}-\mathrm{A}_{3}-\mathrm{A}_{4}-\mathrm{A}_{5}-\mathrm{A}_{0}$ before tool extraction began. At keyhole II, the probe rotation was stopped more quickly after the activation of weld termination. Thus, the probe did not reach the home position but was left on its way home: position $\mathrm{A}_{3}$.

\subsection{Keyhole material flow and its formation mechanism}

The track followed by the probe after activation of weld termination was caused by the reaction force between the probe and workpiece materials. The probe travel after activation of weld termination caused a additional material flow around the probe, which is defined as keyhole material flow (KMF) in this study, as the flow pattern of KMF is different from that during steady state FSW. 
Fig. 3a shows that the probe deflected toward the AS and trailing side (TS) during FSW under the action of high reaction force along the leading side (LS) and retreading side (RS). After activation of weld termination (Fig. 3b), the materials along the LS and RS were swept by the probe and displaced to the RS and TS. As time went on, increasing workpiece material along the LS and RS was displaced to the TS with the probe rotation. After 0.6 second of the weld termination, the leading boundary of the KMF has been driven to the AS (Fig. 3c). For keyhole II, the probe rotation was stopped at this time and the leading boundary of the KMF ceased at the AS, as indicated by the arrow in Fig. 4b. For keyhole I, the probe rotation did not terminate. Under this condition, more material distributed along the LS and RS was swept into the KMF (Fig. 3d). After 2 second of the weld termination, the probe has been totally surround by KMF layer and pushed back to its home position, as indicated in Fig. 3e.

In this study, the eccentricity of probe rotation was measured to be about $30 \mu \mathrm{m}$ when the probe rotated in the air. This eccentricity maybe reduced during FSW under the interaction force between the probe and workpiece material, but did not disappear. After the probe had returned to its home position, in-situ eccentric rotation of the probe expanded the keyhole and caused the probe surface to lose contact with the workpiece. Thus, the KMF stopped due to the insufficient driving force after the probe returned to its home position. 

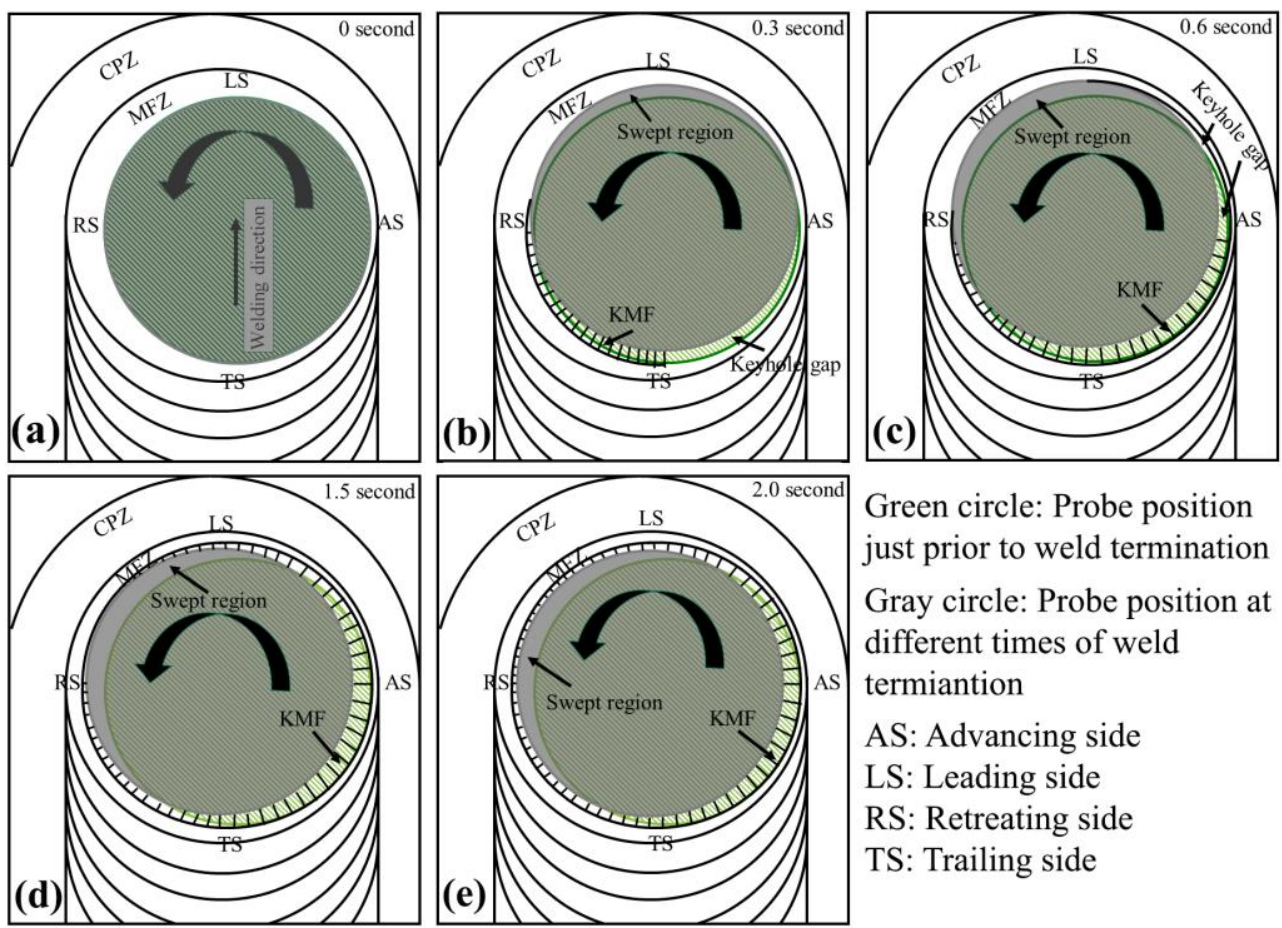

Green circle: Probe position just prior to weld termination Gray circle: Probe position at different times of weld termiantion

AS: Advancing side

LS: Leading side

RS: Retreating side

TS: Trailing side

Fig. 3. Schematic for formation mechanism of KMF.

\subsection{Dimension of keyhole material flow zone}

The formation mechanism of the KMF has been analyzed above, but the exact dimension of the KMF zone is still unknown. This can be accessed through microstructure examination around the keyholes.

The EBSD examination regions around keyholes I and II were marked in Fig. 4. The EBSD maps obtained from keyholes I and II are shown in Figs. 5 and 6, respectively. Since the probe in keyhole I continued to rotate during weld termination, a ring-shaped KMF zone developed around the keyhole (Fig. 3e). Each of the EBSD maps in Fig. 5 contained a layer of the KMF. Due to the emergency weld termination, KMF did not rotate to the LS but terminated at the AS as indicated by the arrow in Fig. 4b. The EBSD maps in Fig. 6 did not include any KMF zone. 

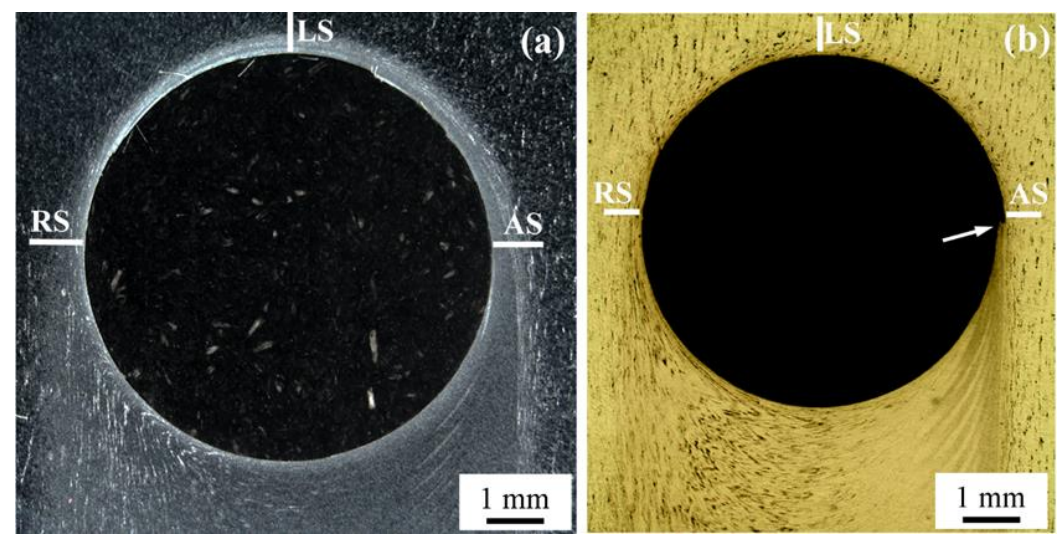

Fig. 4. EBSD examination region around (a) keyhole I and (b) keyhole II.

In order to determine the boundaries of the KMF zone in Fig. 5, the microstructural details of the fine grain regions in Figs. 5 and 6 were compared. Fig. 7 shows that the fine-grained zone around keyhole I can be divided in to two sub-zones: sub-zone I and sub-zone II. In each subzone, the percentage of LAGBs decreased monotonically and the ratio of twin boundaries increased monotonically as material approached the keyhole edge. There is a transition zone between sub-zone I and II around keyhole I. Within the transition zone, there is a step-wise change in the percentage of twin boundaries and LAGBs (Fig. 7), indicating that the deformation history changed significantly at that location. In the fine grain zone around keyhole II, the percentage of LAGBs decreased monotonically and the ratio of twin boundaries increased monotonically as material approached the keyhole (Fig. 8). The second sub-zone was not observed around keyhole II indicating that the sub-zone II, closed to the edge of keyhole I, is the KMF zone. 


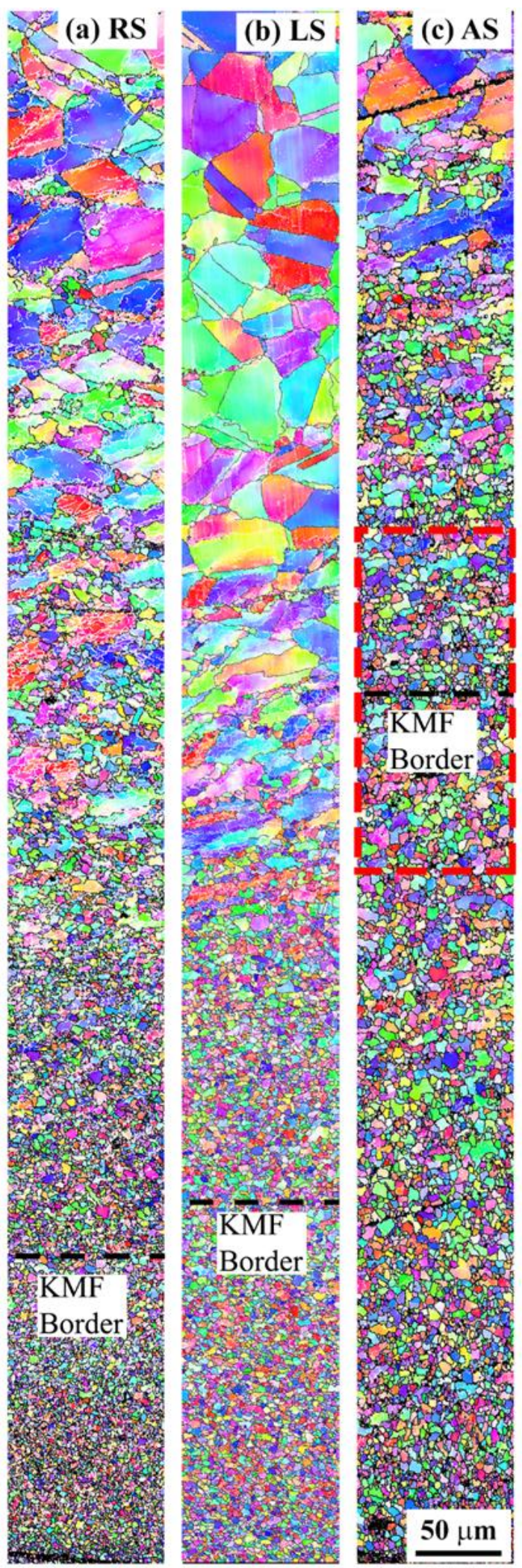

Keyhole edge

Fig. 5. EBSD maps obtained around keyhole I.

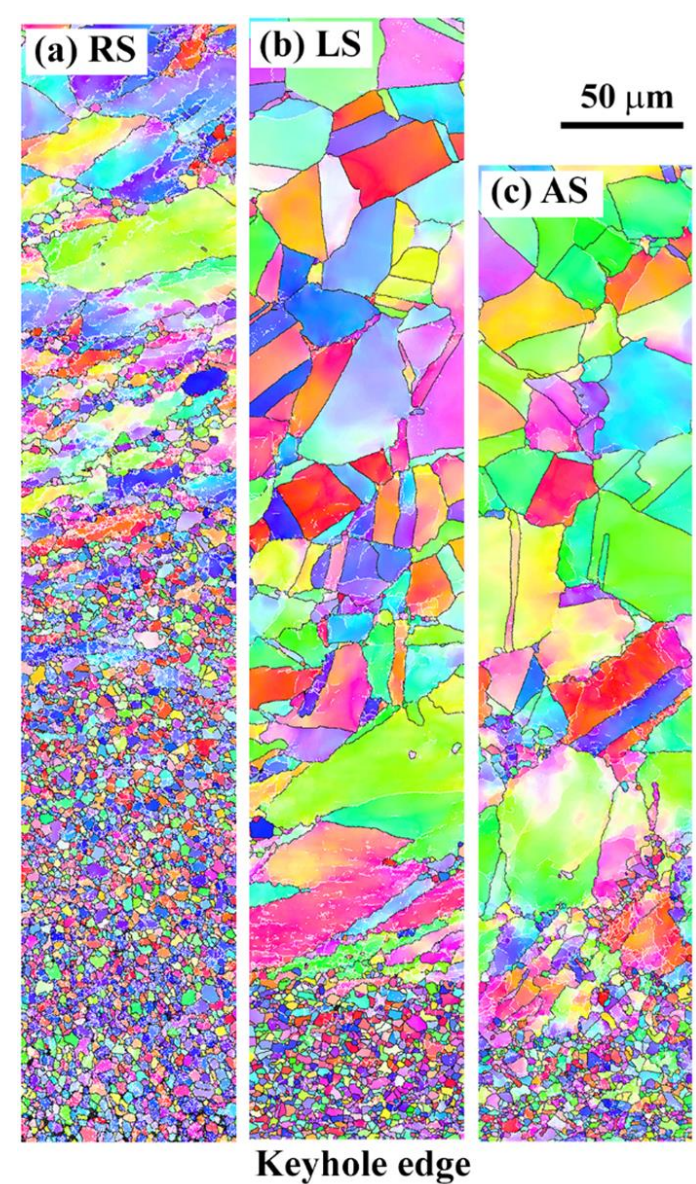

Fig. 6. EBSD maps obtained around keyhole II. 

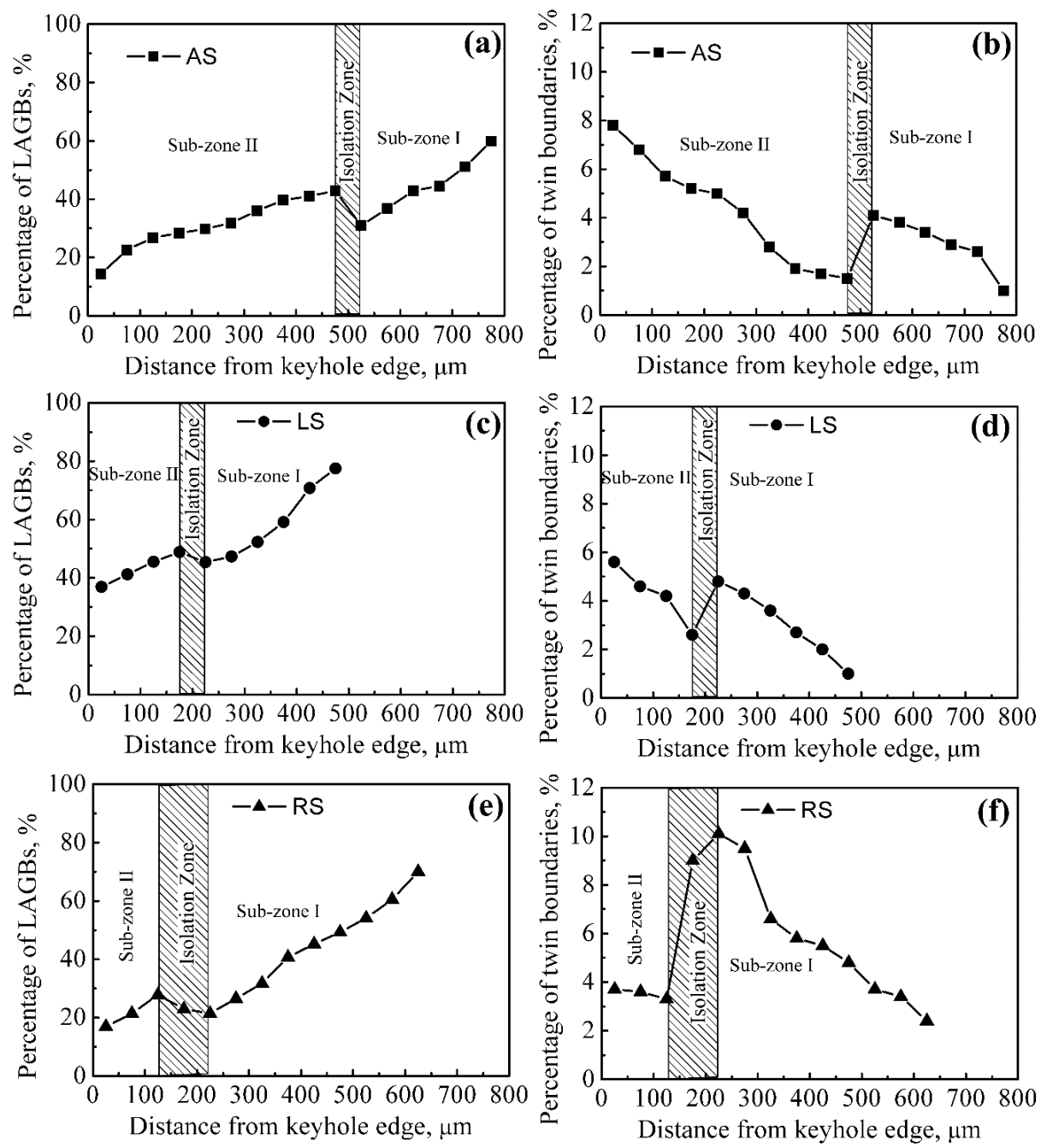

Fig. 7. Distribution of LAGBs and twin boundaries within the fine grain regions in Fig. 5 (keyhole I) at (a) and (b) at AS, (c) and (d) at LS, (e) and (f) at RS.
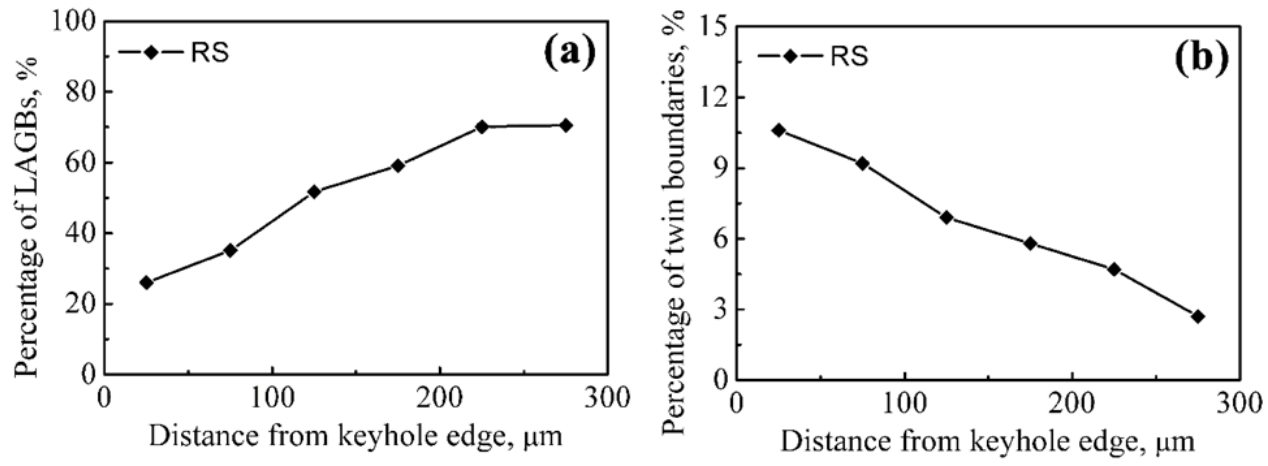

Fig. 8. Distribution of LAGBs and twin boundaries within the fine grain regions in Fig 6 (a) at RS (keyhole II). 
The exact location of the KMF border can be determined through further inspection of the grain boundary map obtained around the isolation zones. A typical example is show in Fig. 9, in which the lower part contains only a few of twin boundaries and the upper part contains more twin boundaries. The dashed line in Fig. 9 was identified as the KMF border. Using this method, the KMF borders at the AS, LS and RS was identified and was marked in Fig. 5 using black dashed lines. The thickness of KMF zone at the AS, LS and RS was determined to be about 500, 220 and $160 \mu \mathrm{m}$, respectively.

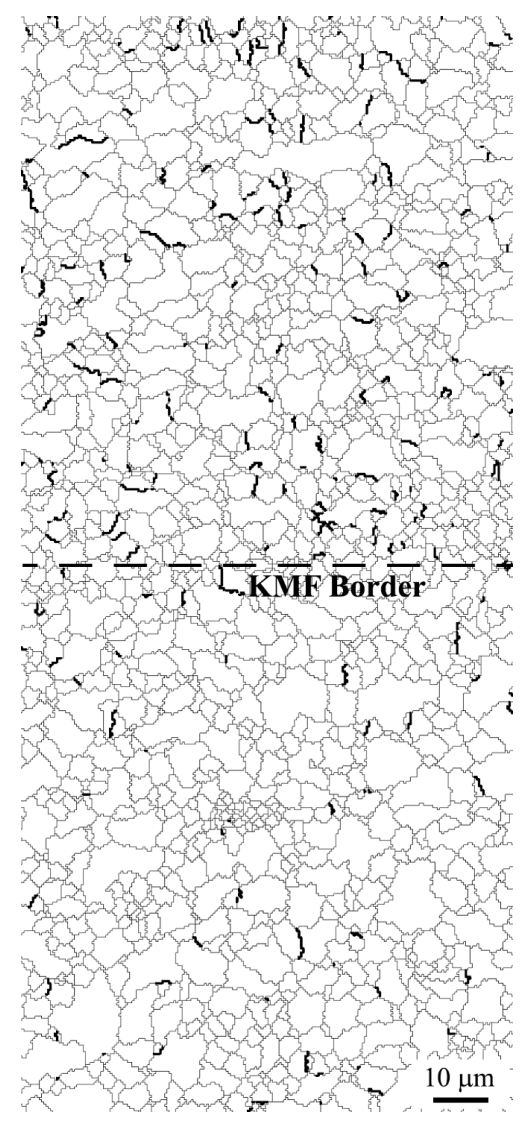

Fig. 9. Grain boundary distribution within the red dashed box in Fig. 5c. (Twin boundary was marked in bold lines)

The microstructure distribution around keyhole II is consistent with previous predictions that the deformation and temperature increased as material neared the probe [27-30]. The enhanced deformation and elevated temperatures promote the recrystallization and development of 
annealing twins. Thus, the fraction of LAGBs decreased close to the keyhole due to enhanced recrystallization and the ratio of twin boundaries increased due to the development of annealing twins.

At keyhole I, the fine-grained material in sub-zones I and II deformed in a similar manner: rotating around the probe. The inner material in each sub-zone experienced higher deformation temperature compared to its outer counterpart in the same sub-zone. Therefore the inner material in each sub-zone has a lower fraction of LAGBs and a higher ratio of twin boundaries. However, Fig. 1 shows that the force acting on the material in the KMF zone (sub-zone II) reduced after activating weld termination. This likely causes a reduction in the strain rate and deformation temperature of the materials in the KMF zone resulting in a change in the fraction of LAGBs and twins was observed at the KMF border.
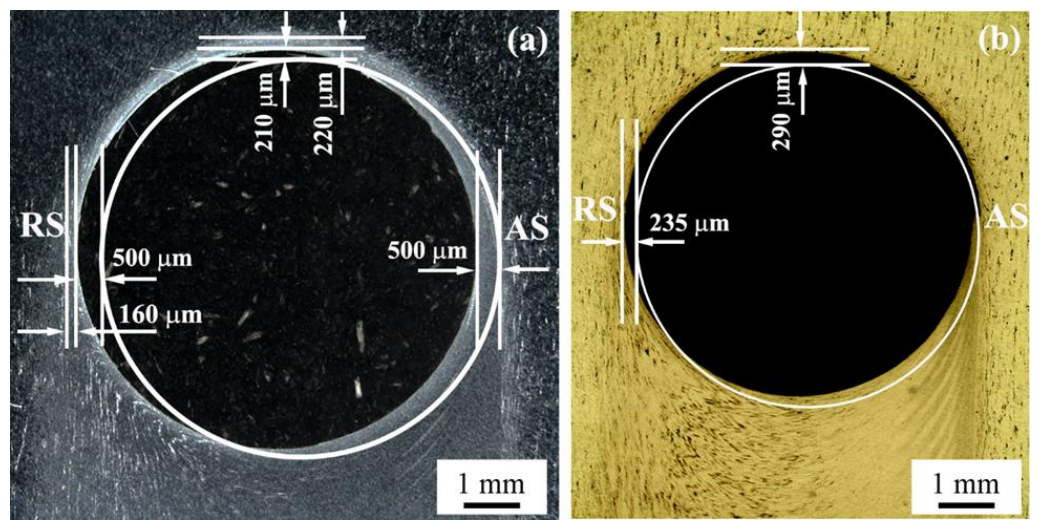

Fig. 10. Probe positions just prior to weld termination close to (a) keyhole I and (b) keyhole II.

\subsection{Probe position just prior to weld termination (termination position)}

Fig. 3e illustrates how the swept region ahead of the probe was filled with KMF before probe extraction. The thickness of $\mathrm{KMF}$ zone at each location during weld termination is proportional to the probe deflection. The probe deflection at the AS, LS and RS of keyhole I was about 500, 220 and $160 \mu \mathrm{m}$, respectively. The corresponding bending force at the AS, LS and RS was determined to be about 1300, 590 and $400 \mathrm{~N}$ (Fig. 1), respectively. According to these data, 
the relationship of probe deflection $\delta(\mu \mathrm{m})$ and the bending forces component $F(\mathrm{~N})$ can be approximately described by the following equation:

$\delta=0.38 F$

According to Eq. [2], the probe position at the moment of activating weld termination was precisely determined and schematically marked in Fig. 10. The probe position at the moment of activating weld termination was defined as 'termination position' as the steady state material flow terminated at this position.

\subsection{Material flow pattern in front of probe during FSW.}

In order to correctly present the material distribution around the probe during steady state FSW instead of that around the keyhole, it is necessary to use the termination position as the reference to determine the material distribution.

Using the termination position as the reference, the EBSD maps obtained around keyhole I and II were displayed in Figs. 11 and 12, respectively. Since the material in the swept region was moved by the probe after activation of weld termination, the microstructural details in the swept region were not available. In order to properly present the spatial distribution of the microstructure, the swept regions were displaced by grey blocks in Figs. 11 and 12. Figs. 3e and 10b shows that part of the swept region around keyhole I was filled by MFZ after weld termination. The grain structure information in MFZ was included in the EBSD maps in Fig. 5. To present the grain structure distribution during steady state welding, the grain structure information in KMF zones should be removed from the EBSD maps as the KMF occurred after the activation of weld termination and did not exist during steady state welding. In Fig. 11, the EBSD maps in KMF zones were cropped as indicated by the black lines. 


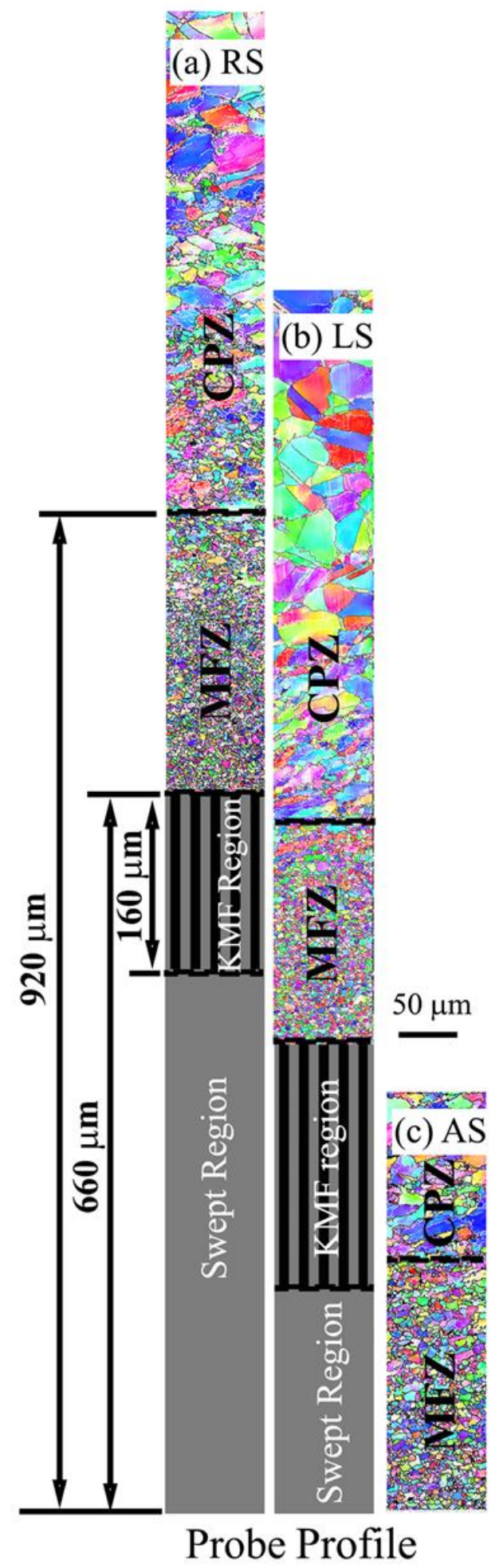

Fig. 11. In-situ microstructure distribution around probe just prior to weld termination (Observation plane is $2 \mathrm{~mm}$ beneath the welding surface).

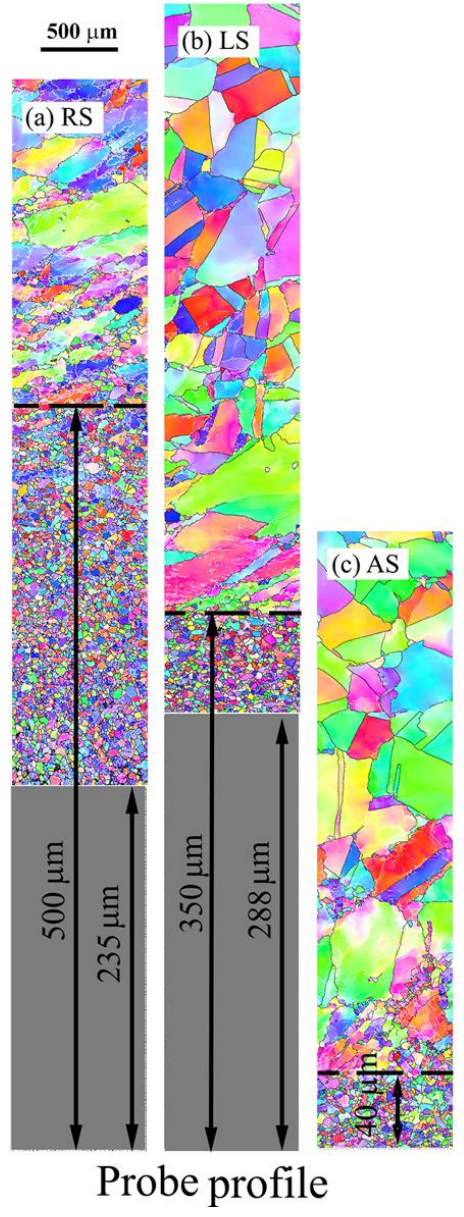

Fig. 12. In-situ microstructure distribution around probe just prior to weld termination (Observation plane is $3 \mathrm{~mm}$ beneath the welding surface). 
Figs. 11 and 12 show that the material ahead of the probe can be divided in to two distinct zones: a material flow zone (MFZ) adjacent to the probe and a compression zone (CPZ) outside of the MFZ. The MFZ was characterized by fine recrystallized grains less than $5 \mu \mathrm{m}$ in diameter. The CPZ consisted of deformed coarse grains and a low fraction of fine recrystallized grains along the HAGBs. The grain sizes in this region were roughly in the range of 10-30 $\mu \mathrm{m}$.

It should be noted that the welding parameters for welds I and II were the same, but the EBSD examination planes of keyhole I and II are 2 and $3 \mathrm{~mm}$, respectively, beneath the welding surface. Therefore, Figs. 11 and 12 displayed the in-situ microstructure distribution at different depth of the weld. The thickness of MFZ in the middle weld layer $(2 \mathrm{~mm}$ beneath welding surface) is approximately 230, 630 and $930 \mu \mathrm{m}$ at the AS, LS and RS, respectively. The thickness of MFZ in the lower weld layer ( $3 \mathrm{~mm}$ beneath welding surface) is approximately 40 , 360 and $500 \mu \mathrm{m}$ at the AS, LS and RS, respectively. The MFZ in each layer increased in thickness from the AS to RS along the probe rotation direction.

Comparing Keyholes I and II, the middle weld layer has a thicker layer of MFZ at the same radial position around the keyhole. This is mainly because the middle welded layer is closer to the shoulder. It deformed at higher temperature and part of its flow may be driven by the rotating shoulder.

\subsection{Materials flow pattern behind probe during FSW}

In order to reveal the material deposition pattern behind the probe, a plate containing markers of 1008 steel slices was subjected to FSW. The probe was extracted after weld termination to avoid tool failure. The microstructure examination was performed on a plane 2 
mm beneath the welding surface. The termination position of the probe was marked by a solid circle in Fig. 13a. Fig. 13a showed that the materials intersecting the path of probe was displaced behind the probe at roughly the same transverse position as its initial position. That is the material near the AS before welding was deposited near the AS after welding while the material close the RS before welding was deposited close to the RS after welding. It is also noted that each marker deformed toward pin rotation direction as it approached the probe, indicating the material ahead of the probe was deformed into the direction of tool rotation.

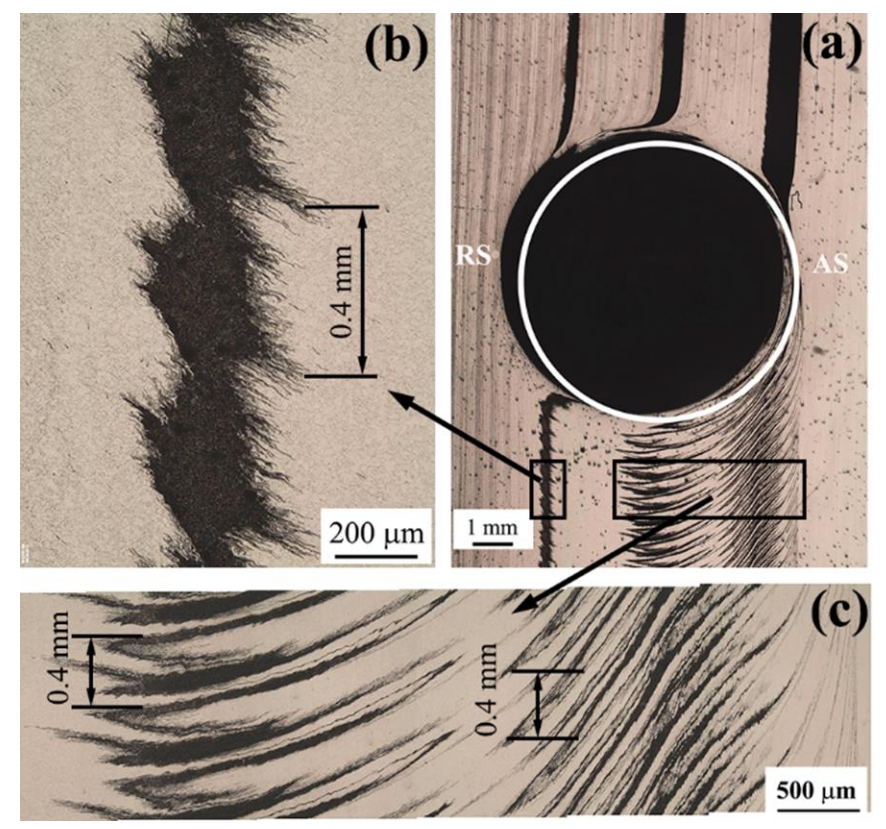

Fig. 13. Plane view of mark material $2 \mathrm{~mm}$ beneath the welding surface: (a) mark distribution around the keyhole; (b) and (c), high magnification of mark distribution in the weld zone.

The 1008 steel close to the RS was less disturbed after FSW (Fig. 13b). In contrast, the markers along the welding centerline and close to the AS broken into long thin arc-shaped fragments which spread roughly along the probe rotation direction (Fig. 13c). The space among the arc-shaped fragments in the welding direction was about $0.4 \mathrm{~mm}$ (Figs. $13 \mathrm{~b}$ and c), which correlates well with the probe advance distance per rotation. 
The formation of arc-shaped fragments might be caused by the eccentric rotation of the probe as well as the threads on the probe surface. It looks like that the material close to the RS were less affected by the eccentric rotation and thread. This can be attributed to the following reasons. First, as the MFZ become thicker close to the RS, the soft material in the inner layer of the MFZ worked as a cushion for the material in the outer layer of the MFZ, reducing the eccentric rotation of the material in the outer layer of the MFZ. Second, the materials deposited close to the RS traveled shorter distance.

\section{Discussion}

\subsection{Model of materials flow driven by probe profile}

The material flow during FSW can be generally divided in to three horizontal layers: (I) upper layer whose material flow is mainly controlled by the shoulder; (II) intermediate layer whose material flow is mainly driven by the probe profile; and (III) bottom layer whose material flow is mainly driven by the probe tip. Note: this discussion assumes that the probe is of sufficient length to extend beyond layers I and II. This study focused on the material flow pattern in the intermediate layer. Based on the analysis of the KMF, EBSD data and marker distribution, the materials flow pattern during FSW can be illustrated using a schematic diagram shown in Fig. 14.

Fig. 14 shows that the thickness of both CPZ and MFZ increased gradually from AS to RS. The formation of such a microstructure distribution can be ascribe to the following process. During FSW, the material at the AS undergoes severe plastic deformation at elevated temperatures and recrystallized rapidly as it is swept by the hot rotating probe. The hightemperature flow resistance of the recrystallized grains decreases significantly due to the grain 
refinement [31-34]. Thus, the recrystallized grains are driven to rotate around the probe along the probe rotation direction, forming the MFZ.

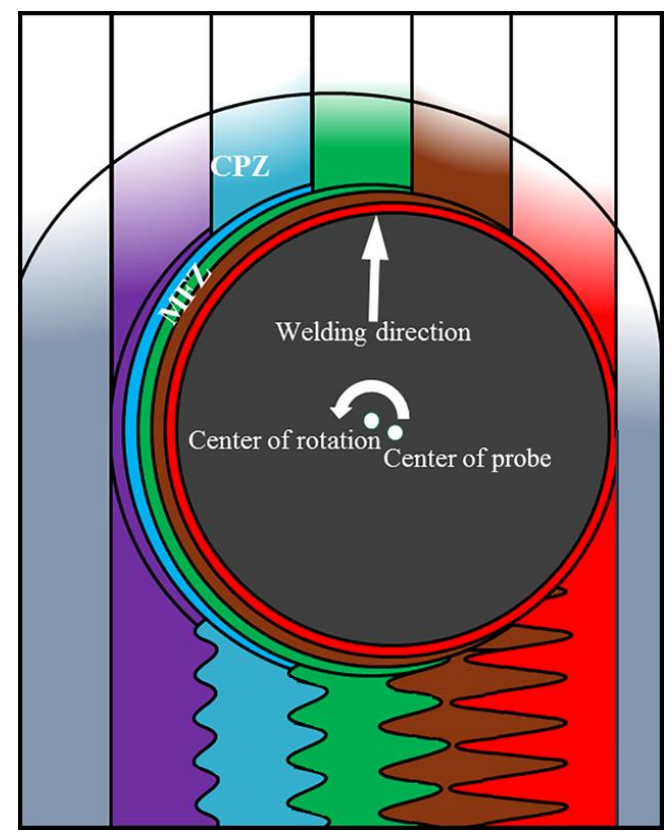

Fig. 14. Material flow pattern around the probe during steady state FSW.

As the base material ahead of the welding tool approaches the probe, it experiences compression deformation at elevated temperature, forming the CPZ. The CPZ mainly consisted of coarse deformed grains. When the material in CPZ collides with the hot material in MFZ, it is heated, deformed and recrystallizes rapidly. As increasing recrystallized material joins the MFZ, the MFZ thickens from AS to RS. As increasing material is compressed into the MFZ, the pressure inside the MFZ would increase from AS to RS, which increases the compression force imposed on $\mathrm{CPZ}$ and thicken the CPZ.

The material in the MFZ is not actually "stirred" in such a manner that would cause mixing between the layers that make up the MFZ. As material enters the MFZ at the leading side of the tool, it flows around the probe much like the extrusion process. As it moves around the probe, the material experiences plastic deformation without significant mixing, i.e. adjacent layers 
remain adjacent to each other during deformation. Additionally, the material generally enters and exists the MFZ in roughly the same transverse location. In this way, most of the material cannot be rotated around the probe more than once during FSW.

\subsection{Influence of material/FSW process on material flow}

In the present study, characteristics regarding material flow and microstructure evolution during FSW were investigated through comprehensive analysis of material flow patterns, microstructure characterization and process forces. As a result, some additional details regarding material flow in FSW were revealed that could elucidate some of the inconsistencies in the literature. A more comprehensive understanding of the FSW flow can be reached through a comparison of the present and previous works.

Schmidt et al. [14] proposed a material flow model similar to the results presented herein. Nandan et al. [27] and Cho et al. [35] also showed similar material flow patterns using the distribution of streamlines in their simulation investigations. In Schmidt's model [14], a rotation zone existed around the probe. The material in rotation zone rotated more than once around the probe. Simulation results from Nandan et al. [27] also showed the presence of nearly circular closed streamlines adjacent to the probe. The recirculating flow region expanded with elevation because of the proximity of the larger rotating shoulder. Recently, Morisada et al. $[11,12,36]$ recorded the movement of a tiny tungsten tracer during FSW using two pairs of X-ray transmission system. Results showed that the tungsten particles pre-embed in the welding plate rotated around the probe several times during FSW, implying that the workpiece material rotated around the probe more than once. However, in present study, the experiment showed that under normal operating conditions, the material did not rotate around the probe more than once. 
There has been much debate in the literature and FSW community regarding whether or not the materials in the weld nugget rotates around the probe more than once during FSW. The current authors believe that this depends on the tool geometry, the properties of the parent material, and the welding parameters.

The previous investigations have shown that the tool geometry have a great influence on the material flow $[37,38]$. The shoulder-driven material and pin-driven material flow in different manners. In the experiment of Morisada et al. [11,12,34], the cylindrical probe used was short with a large diameter, i.e. $6 \mathrm{~mm}$. The probe length was $3.0 \mathrm{~mm}$ for welding pure $\mathrm{Al}$, and $1.9 \mathrm{~mm}$ for welding both pure $\mathrm{Al}$ and low carbon steel. Previous investigations have shown that when a rotating tool without probe is used, material flow has reached $2 \mathrm{~mm}$ below the shoulder of the tool $[39,40]$. Therefore, when the length of the probe does not exceed the depth of the material deformed by the shoulder, material flow is primarily influenced by the rotating shoulder. When material flow is primarily driven by shoulder, the welding process can be treated as an in-situ high-pressure-torsion (HPT) rather than an in-situ extrusion traveling long the welding region. This would explain why Morisida et al. [11,12,34] observed material rotating more than once around the tool.

The nature of parent material also effects material flow during FSW. During FSW, material in the MFZ is softened significantly at elevated temperatures. Adjacent the weld nugget, strength rises rapidly in the HAZ and base material in most engineering aluminum alloys as a result of strengthening precipitates. When this occurs, the stronger HAZ and base metal create a "die" on both sides of the tool probe. Therefore, the weld area is only slightly wider than the diameter of the probe when engineering alloys, such as age-hardening Al alloys or stainless steel, were subjected to FSW $[2,6,41,42]$. As material in the MFZ rotates around the probe to the AS, it is 
difficult for this thin layer to pass through the narrow gap at the AS between the probe, and the stiff base material which is moving in the opposite direction.

In contrast, the difference in strength at MFZ/HAZ in pure $\mathrm{Al}$ is relative small because there are no strengthening precipitates. High thermal conductivity and a lack of strengthening precipitates results in a very wide "die" (or no "die"). Thus, when FSW pure Al the weld area is significantly wider than the diameter of the probe $[20,21,43,44]$. The enlarged gap at the AS between the probe and the only slightly stronger base material allows material in the MFZ to rotate more than once around the tool.

Material flow in FSW is also strongly influenced by the welding parameters. High thermal input welding parameters (such as high rotation rate and low welding speed) can create a wider MFZ and HAZ. This produces a wider "die" at the AS between the probe and HAZ or base material. This scenario may allow some material in the MFZ to pass through the "die" on the AS. When low thermal input welding parameters are used, the weld area is only slightly wider than the probe, creating a narrow "die". Under these conditions, it would be difficult for material to rotate more than once.

Although high thermal input welding parameters have been used in FSW investigation to understand FSW limitation, low thermal input welding parameters are usually recommend in industry applications as they generally associated with better properties, productivity and energy efficiency. However, welding defects may generate when the thermal input is too low. Thus, the welding parameters need to be carefully adjusted to optimize the material flow and avoid defects. The welding parameters used in this investigation which were considered low thermal input were selected according to the above considerations. The combination of low energy welds and low thermal conductivity of the $304 \mathrm{~L}$ base materials established a very narrow "die" at the AS. There 
was no evidence that material within the MFZ which is driven by the probe profile rotated around the probe more than once under steady state conditions.

In summary, the material may rotate around the pin more than once during FSW under the following conditions: (1) the material flow is controlled by shoulder; (2) FSW conducted at high thermal input parameters; or (3) difference in elevated temperature strength of the MFZ and HAZ are small.

\section{Conclusions}

(1) Contact forces between the welding tool and the workpiece material cause the probe to deflect away from its "home" position during FSW: toward the advancing side of the weld and opposite the direction of the travel. Once weld termination is activated, system relaxation allowed the probe to return to its "home" position along an arc route prior to tool extraction. This produced non-steady state material flow (KMF) around the keyhole, altering the in-situ material distribution formed during FSW.

(2) Microstructure distribution just prior to weld termination was determined and the nature of material flow during FSW was preserved by tracking the probe route and the KMF occurred during weld termination.

(3) During FSW, two distinct deformation regions formed in sequence ahead of the probe: a compression zone (CPZ) and a material flow zone (MFZ) adjacent to the probe. The CPZ mainly consisted of coarse deformed grains. The MFZ was characterized by fine recrystallized grains.

(4) A material flow model was established to describe the in-situ material flow pattern during FSW. As the base material approaches the probe during FSW, it was compressed initially, forming a compression zone $(\mathrm{CPZ})$. When the coarse deformed grains in $\mathrm{CPZ}$ collided with the hot material in MFZ, these recrystallized rapidly and joined the MFZ, thickening the MFZ ahead 
of the probe. During FSW, material intersecting the path of probe was displaced around the probe and deposited behind the probe at roughly the same transverse position as its initial position.

\section{Acknowledgements}

The authors thank the National Science Foundation (under award number 1405508) for financial support of this work.

\section{Reference}

[1] W.M. Thomas, Friction stir butt welding. International patent PCT/GB92/02203; 1991.

[2] F.C. Liu, Z.Y. Ma, Influence of tool dimension and welding parameters on microstructure and mechanical properties of friction-stir-welded 6061-T651 aluminum alloy, Metall. Mater. Trans. A 39 (2008) 2378-2388.

[3] M. Peel, A. Steuwer, M. Preuss, P.J. Withers, Microstructure, mechanical properties and residual stresses as a function of welding speed in aluminium AA5083 friction stir welds, Acta Mater. 51 (2003) 4791-4801.

[4] Y.S. Sato, T.W. Nelson, C.J. Sterling, Recrystallization in type 304L stainless steel during friction stirring, Acta Mater. 53 (2005) 637-645.

[5] J.J. Pang, F.C. Liu, J. Liu, M.J. Tan, D.J. Blackwood, Friction stir processing of aluminium alloy AA7075: Microstructure, surface chemistry and corrosion resistance, Corr. Sci. 22 (2016) 217-228.

[6] J.Q. Su, T.W. Nelson, R. Mishra, M. Mahoney, Microstructural investigation of friction stir welded 7050-T651 aluminum, Acta Mater. 51 (2003) 713-729. 
[7] A.H. Feng, Z.Y. Ma, Microstructural evolution of cast Mg-Al-Zn during friction stir processing and subsequent aging, Acta Mater. 57 (2009) 4248-4260.

[8] Z.Y. Ma, F.C. Liu, R.S. Mishra, Superplastic deformation mechanism of an ultrafine-grained aluminum alloy produced by friction stir processing, Acta Mater. 58 (2010) 4693-4704.

[9] S. Mironov, Y.S. Sato, H. Kokawa, H. Inoue, S. Tsuge, Structural response of superaustenitic stainless steel to friction stir welding, Acta Mater. 59 (2011) 5472-5481.

[10] K. Colligan, Material flow behavior during friction stir welding of aluminum, Weld. J. 78 (1999) 229S-237S.

[11] Y. Morisada, H. Fujii, Y. Kawahito, K. Nakata, M. Tanaka, Three-dimensional visualization of material flow during friction stir welding by two pairs of X-ray transmission systems. Scripta Mater. 65 (2011) 1085-1088.

[12] Y. Morisada, T. Imaizumi, H. Fujii, Clarification of material flow and defect formation during friction stir welding. Sci. Technol. Weld. Join. 20 (2015) 130-137.

[13] A.P. Reynolds, Visualization of material flow in autogenous friction stir welds, Sci. Technol. Weld. Join. 5 (2000) 120-124.

[14] N.H.B. Schmidt, T.L. Dickerson, J.H. Hattel, Material flow in butt friction stir welds in AA2024-T3, Acta Mater. 54 (2006) 1199-1209.

[15] Y.S. Sato, H. Kokawa, K. Ikeda, M. Enomoto, S. Jogan, T. Hashimoto, Microtexture in the friction-stir weld of an aluminum alloy, Metall. Mater. Trans. A 32 (2001) 941-948.

[16] D.P. Field, T.W. Nelson, Y. Hovanski, K.V. Jata, Heterogeneity of crystallographic texture in friction stir welds of aluminum, Metall. Mater. Trans. A 32 (2001) 2869-2877.

[17] S.H.C. Park, Y.S. Sato, H. Kokawa, Basal plane texture and flow pattern in friction stir weld of a magnesium alloy, Metall. Mater. Trans. A 34 (2003) 987-994. 
[18] U.F.H.R. Suhuddin, S. Mironov, Y.S. Sato, H. Kokawa, C.W. Lee, Grain structure evolution during friction stir welding of AZ31 magnesium alloy, Acta Mater. 57 (2009) 5406-5418.

[19] F.C. Liu, Z.Y. Ma, M.J. Tan, Facilitating basal slip to increase deformation ability in MgMn-Ce alloy by textural reconstruction using friction stir processing, Metall. Mater. Trans. A 44 (2013) 3947-3960.

[20] S. Mironov, Y.S. Sato, H. Kokawa, Development of grain structure during friction stir welding of pure titanium, Acta Mater., 57 (2009) 4519-4528.

[21] F.C. Liu, j. Liao, Y. Gao, K. Nakata, Influence of texture on strain localization in stir zone of friction stir welded titanium, J. Alloys Comp. 626 (2015) 304-308.

[22] K.E. Knipling, R.W. Fonda. Texture development in the stir zone of near- $\alpha$ titanium friction stir welds, Scripta Mater. 60 (2009) 1097-1100.

[23] P.B. Prangnell, C.P. Heason, Grain structure formation during friction stir welding observed by the 'stop action technique', Acta Mater. 53 (2005) 3179-3192.

[24] R.W. Fonda, K.E. Knipling, J.F. Bingert, Microstructural evolution ahead of the tool in aluminum friction stir welds, Scripta Mater. 58 (2007) 343-348.

[25] S. Mironov, T. Onuma, Y.S. Sato, H. Kokawa, Microstructure evolution during friction-stir welding of AZ31 magnesium alloy, Acta Mater. 100 (2015) 301-312.

[26] M.F. Ashby, Materials selection in mechanical design, fourth ed., Elsevier, 2011, PP. 532533

[27] R. Nandan, G.G. Roy, T.J. Lienert, T. Debroy. Three-dimensional heat and material flow during friction stir welding of mild steel, Acta Mater. 55 (2007) 883-895.

[28] X.X. Zhang, B.L. Xiao, Z.Y. Ma, A transient thermal model for friction stir weld part II: Effects of weld conditions, Metall. Mater. Trans. 42A (2011) 3229-3239. 
[29] W. Han, A. Kimura, N. Tsuda, H. Serizawa, D. Chen, H. Je, H. Fujii, Y. Ha, Y. Morisada, H. Noto, Effects of mechanical force on grain structures of friction stir welded oxide dispersion strengthened ferritic steel, J. Nucl. Mater. 455 (2014) 46-50.

[30] W. Han, D. Chen D, Y. Ha, et al. Modifications of grain-boundary structure by friction stir welding in the joint of nano-structured oxide dispersion strengthened ferritic steel and reduced activation martensitic steel, Scripta Mater. 105 (2015) 2-5.

[31] K. Wang, F.C. Liu, P. Xue, D. Wang, B.L. Xiao, Z.Y. Ma, Superplastic constitutive equation including percentage of high-angle grain boundaries as a microstructural parameter, Metall. Mater. Trans. 47A (2015) 546-559.

[32] F.C. Liu, Z.Y. Ma, Contribution of grain boundary sliding in low-temperature superplasticity of ultrafine-grained aluminum alloys, Scripta Mater. 62 (2010) 125-128.

[33] F.C. Liu, P. Xue, Z.Y. Ma. Microstructural evolution in recrystallized and unrecrystallized Al-Mg-Sc alloys during superplastic deformation, Mater. Sci. Eng. A 547 (2012) 55-63.

[34] F.C. Liu, Z.Y. Ma, Achieving high strain rate superplasticity in cast 7075Al alloy via friction stir processing, J. Mater. Sci. 44 (2009) 2647-2655.

[35] H.H. Cho, S.T. Hong, J.H. Roh, H.S. Choi, S.H. Kang, R.J. Steel, H.N. Han, Threedimensional numerical and experimental investigation on friction stir welding processes of ferritic stainless steel, Acta Mater. 61 (2013) 2649-2661.

[36] Y. Morisada, T. Imaizumi, H. Fujii, M. Matsushita, R. Ikeda, Three-dimensional visualization of material flow during friction stir welding of steel and aluminum, J. Mater. Eng. Perform. 23 (2014) 4143-4147.

[37] K. Kumar, S.V. Kailas, The role of friction stir welding tool on material flow and weld formation, Mater. Sci. Eng. A 485 (2008) 367-374. 
[38] R.M. Leal, C. Leitão, A. Loureiro, D.M. Rodrigues, P. Vilaca, Material flow in heterogeneous friction stir welding of thin aluminium sheets: Effect of shoulder geometry, Mater. Sci. Eng. A 498 (2008) 384-391.

[39] Y. Tozaki, Y. Uematsu, K. Tokaji, A newly developed tool without probe for friction stir spot welding and its performance, J. Mater. Process. Technol. 210 (2010) 844-851.

[40] L.G. Zhang, S.D. Ji, G.H. Luan, C.L. Dong, L. Fu, Friction stir welding of Al alloy thin plate by rotational tool without pin, J. Mater. Sci. Technol. 27 (2011) 647-652.

[41] S.H.C. Park, Y.S. Sato, H. Kokawa, K. Okamoto, S. Hirano, M. Inagaki, Rapid formation of the sigma phase in 304 stainless steel during friction stir welding, Scripta Mater. 49 (2003) 11751180.

[42] F.C. Liu, Z.Y. Ma, Low-temperature superplasticity of friction stir processed Al-Zn-Mg-Cu alloy, Scripta Mater. 58 (2008) 667-670.

[43] Y. Gao, K. Nakata, K. Nagatsuka, F.C. Liu, J. Liao, Interface microstructural control by probe length adjustment in friction stir welding of titanium and steel lap joint, Mater. Des. 65 (2015) 17-23.

[44] T. Morishige, T. Hirata, M. Tsujikawa, K. Higashi, Comprehensive analysis of minimum grain size in pure aluminum using friction stir processing, Mater. Lett. 64 (2010) 1905-1908. 

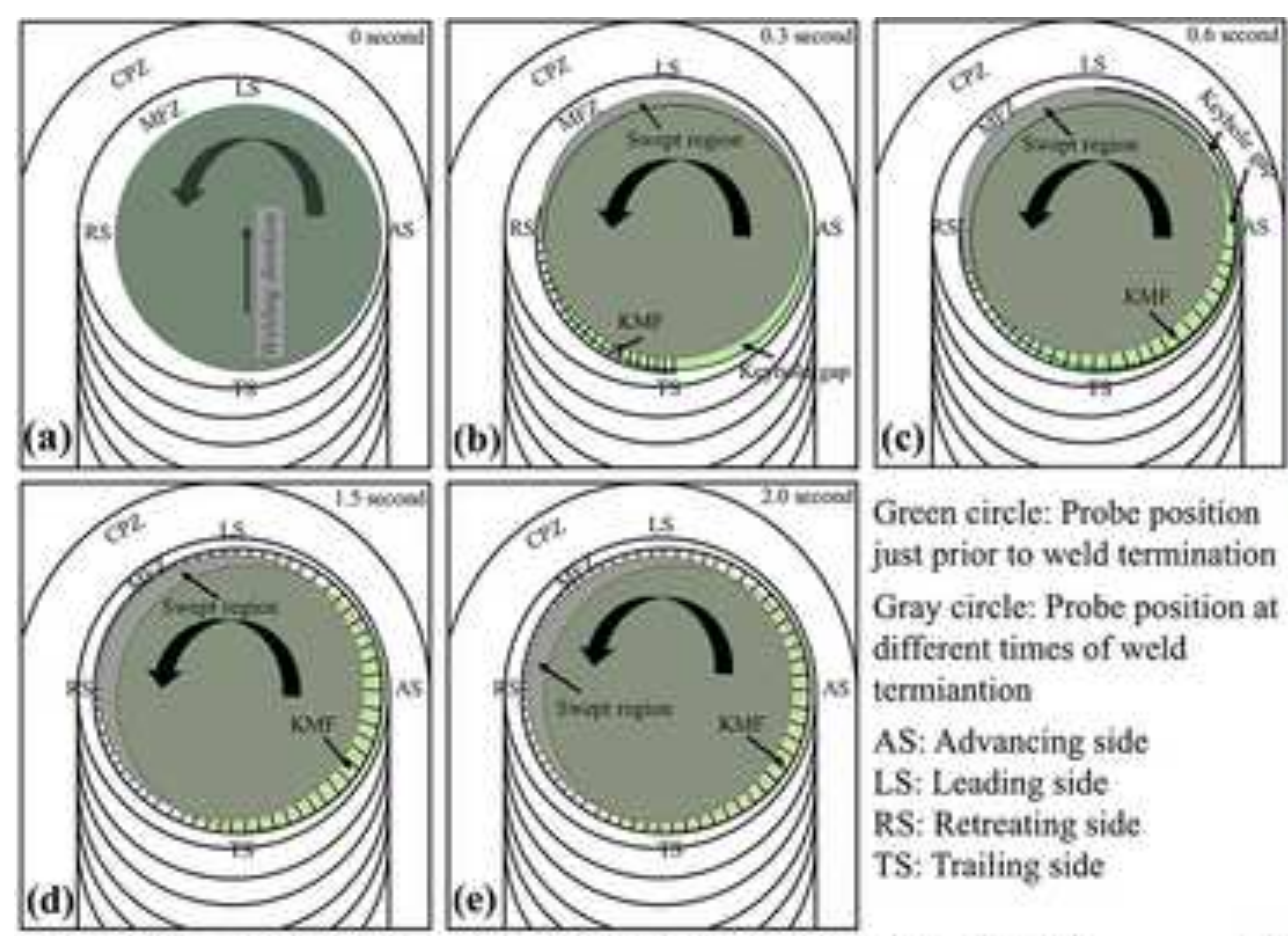

Green circle: Probe position just prior to weld termination Gray circle: Probe position at different times of weld termiantion

AS: Advancing side

LS: Leading side

RS: Retreating side.

TS: Trailing side

Formation mechanism of a additional material flow (KMF) around keyhole during weld termination

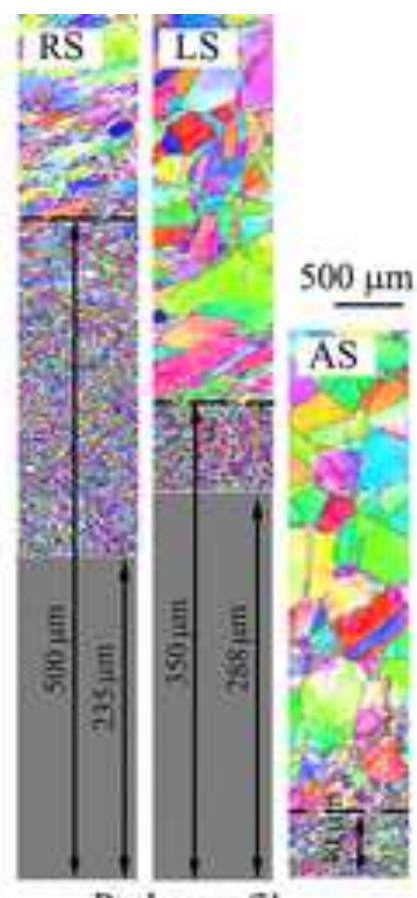

Probe profile

Microstructure distribution during steady state FSW

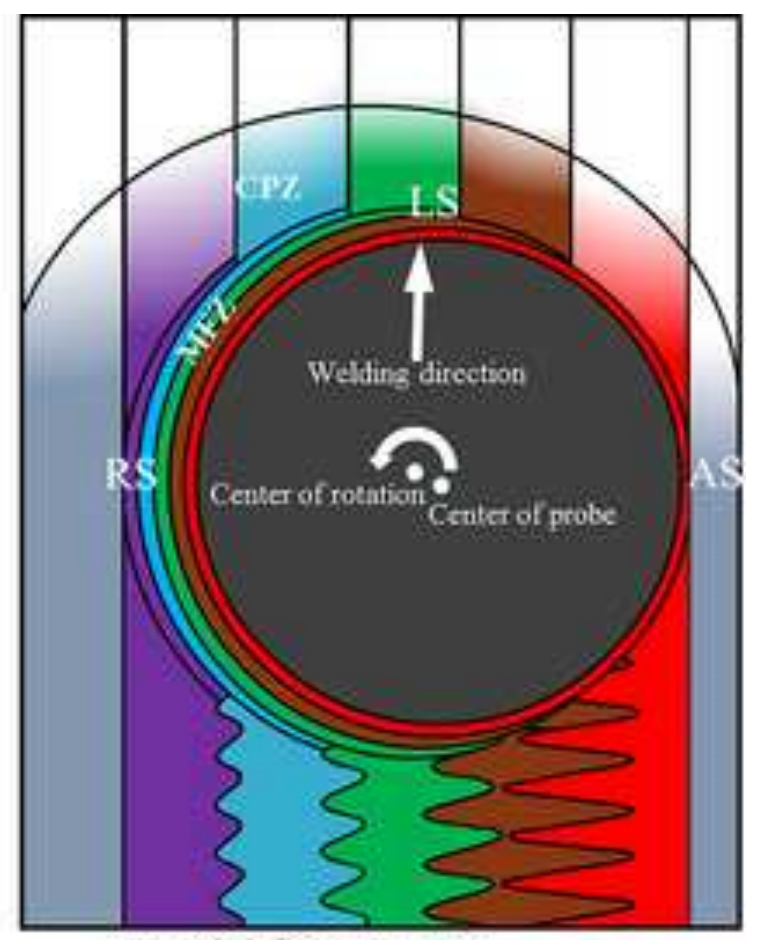

Material flow pattern during steady state FSW 